San Jose State University

From the SelectedWorks of Tianqin (Kelly) Shi

2018

The quest for carbon-neutral industrial operations: renewable power purchase versus distributed generation

Tongdan Jin, Texas State University - San Marcos

Tianqin Shi, San Jose State University

Taeho Park, San Jose State University

Available at: https://works.bepress.com/tianqin-shi/5/ 


\title{
The Quest for Carbon-Neutral Industrial Operations: Renewable Power Purchase versus Distributed Generation
}

\author{
Tongdan Jin ${ }^{\mathrm{a}}$, Tianqin Shi ${ }^{\mathrm{b} *}$ and Taeho $\operatorname{Park}^{\mathrm{b}}$ \\ angram School of Engineering, Texas State University, San Marcos, TX, USA;

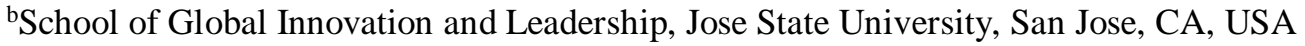 \\ *Corresponding author. Email: tianqin.shi@ sjsu.edu
}

\begin{abstract}
Integrating renewable energy into the manufacturing facility is the ultimate key to realizing carbon-neutral operations. Although many firms have taken various initiatives to reduce the carbon footprint of their facilities, there are few quantitative studies focused on cost analysis and supply reliability of integrating intermittent wind and solar power. This paper aims to fill this gap by addressing the following question: shall we adopt power purchase agreement (PPA) or onsite renewable generation to realize the eco-economic benefits? We tackle this complex decision-making problem by considering two regulatory options: government carbon incentives and utility pricing scheme. A stochastic programing model is formulated to search for the optimal mix of onsite and offsite renewable power supply. The model is tested extensively in different regions under various climatic conditions. Three findings are obtained. First, in a long term onsite generation and PPA can avoid the price volatility in the spot or wholesale electricity market. Second, at locations where the wind speed is below $6 \mathrm{~m} / \mathrm{s}$, PPA at $\$ 70 / \mathrm{MWh}$ is preferred over onsite wind generation. Third, compared to PPA and wind generation, solar generation is not economically competitive unless the equipment cost is down below $\$ 1.5 \mathrm{M} / \mathrm{MW}$.
\end{abstract}

Keywords: Zero carbon operations, power purchase agreement, distributed energy resource, sustainable manufacturing, demand response 


\section{Introduction}

The industrial sector accounts for almost one-third of primary energy use worldwide in 2007, and approximately 25 percent of world carbon dioxide (CO2) emissions are resulted from the energy use of industrial processes (IEA 2008). A typical semiconductor fab facility requires 15-30 Megawatts (MW) power to maintain its routine production (Hu and Chuah, 2003). This is equivalent to emitting 100-200 thousand tons of carbon per annum because the majority of today's electricity is generated from burning fossil fuels. To produce one MWh of electricity, on average 704 kilograms $(\mathrm{Kg})$ of $\mathrm{CO}_{2}$ is released to the air when burning coal, gas, or oil (EIA 2016). In addition to the environmental impact, the annual utility bills of the facility reach as high as $\$ 20$ million. The carbon footprint becomes more severe in heavy industries, such as steel, oil refinery and cement production, where a single facility using conventional electricity is responsible for up to 4-5 million tons of carbon emissions per annum (Tang et al. 2014). Hence, reversing the climate change and lowering the energy cost are the main impetuses driving the manufacturing industries to seek a cost-effective and eco-friendly energy solution.

To battle the climate change, many industrial consumers view renewable energy as the key to mitigating the environmental impacts and attaining business sustainability. There are two green technologies currently adopted by industries to achieve low-carbon operations: power purchase agreement (PPA), and onsite renewable generation. In PPA, consumers directly sign a long-term contract with large wind and solar farms for buying renewable electric energy. In the first half of 2015 alone, nearly 1,600 MW of renewables capacity was contracted through corporate PPAs in the USA (Baker and McKenzie 2015), as opposed to a total of 650 MW from 2008 to 2012 (Staple and Bromaghim, 2015). In fact, the contractual price in 2015 is surprisingly low and down to the average of \$50/MWh compared to over \$100/MWh in 2008 (Bolinger et al. 2015). Companies leading the PPA include Google, Walmart, Amazon, Facebook, Dow Chemical, Apple, and Microsoft. For instance, Google's overall contracted renewable power capacity has reached 2,000 MW in 2015. The company plans to triple its energy purchases with the goal of attaining 100 percent of renewable operations for its facilities worldwide by 2025 (Huddleston 2015). While the price is often fixed with relatively low rate, these long term energy contracts could last for 15-20 years. PPA is considered as a win-win energy agreement between renewable energy developers and large industrial consumers. On one hand, it secures the revenue stream of the renewable energy developer despite of the generation intermittency. On the other hand, consumers are able to achieve the environmental commitment as well as ward off the price volatility in the spot or wholesale market. 
Onsite generation, also known as distributed generation (DG), is another viable approach to realizing low carbon operation. A DG system usually consists of one or several distributed energy resources (DER) that are installed near the industrial facility for power generation. Typical DER units include wind turbines (WT), solar photovoltaics (PV), fuel cells, micro-turbines, and diesel engines. The capacity of a DER unit is relatively small in a range between $50 \mathrm{KW}$ to $10 \mathrm{MW}$. Onsite WT and PV systems are particularly appealing because they have several advantages, such as reducing carbon emissions, mitigating transmission losses and strengthening grid resilience. For instance, Honda installed two WT units at its transmission plant in Russells Point, Ohio in 2013 (Stinpetru 2014). Both turbines can produce 67-72 MWh per day at the high wind speed, satisfying 16 percent of electricity need of the plant. Anheuser-Busch's Budweiser facility in Fairfield, California installed 3.1 MW wind capacity and 1.2 MW PV array (6,500 panels), providing 40 percent of the green electricity to the brewery factory (Hickey 2014). Word-wide, a total of 142,000 MW DG capacity including wind and solar is installed in 2012, representing 39 percent share of new capacity addition (Ovens 2014).

Though renewable DG technologies are promising, the main obstacles to the large-scale use of these technology are the power intermittency and installation cost. First, the output of WT and PV is difficult to predict due to the stochastic wind speed and weather condition. Energy storage systems can resolve the power intermittency issue, but low-cost, high-density storage systems are still not available. Second, the cost of installing and maintaining PV units is still expensive compared with the centralized generation. To facilitate the integration of onsite wind and solar generation, two fundamental questions shall be addressed. First, which energy solution is more cost-effective: PPA or wind- and solar-based DG system? Second, is it technically feasible to harness onsite wind and solar power to achieve zero-carbon industrial operations without energy storage? To answer both questions, this paper proposes a stochastic optimization model to investigate the trade-off between PPA and a DG system in terms of energy reliability, system cost and environmental benefits. We propose a grid-connected DG system comprised of WT, PV, and PPA to power a medium-size industrial facility, and optimize the generation capacity by achieving the following goals: 1) minimizing levelized cost of energy; and 2) attaining zero carbon emissions. To verify and validate the proposed solution, the proposed energy model is tested in ten different locations of the world with diverse climatic conditions.

The contributions of the paper are twofold. First, we present a quantitative method to seek a zero-carbon industrial operations through the synthesis of PPA and DG system. 
Although PPA and DG have been discussed extensively in literature, a joint energy supply model with both PPA and DG has rarely been investigated. Second, the results from this study can be used as a guideline for industrial consumers to determine the best energy strategy to attain carbon-neutral operations in the presence of uncertainties, including climatic conditions, utility price, and government regulations. It also serves as a benchmark to compare with other environmental initiative programs, such as energy efficiency, carbon tax, and carbon trade-andcap.

The remainder of the paper is organized as follows. Section 2 reviews existing lowcarbon operational methods in industries. Section 3 describes the working principle of the gridconnected DG system, and formulates our stochastic planning model that optimizes the capacity mix of onsite and offsite renewable power. Section 4 performs cost-benefit analyses of the DG system using design of experiments. In Section 5, actual climatic data from ten locations of the world are used to test the feasibility of the proposed energy solution. Section 6 concludes the paper. Abbreviations of major terminology are provided below.

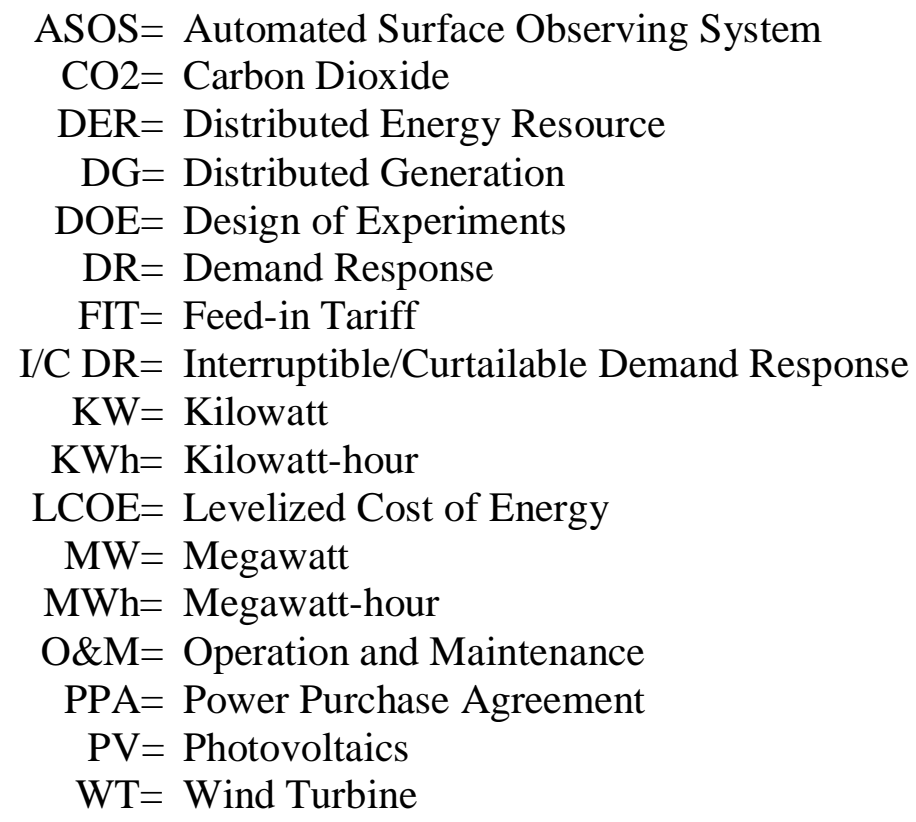

\section{Literature Review}

Existing literature pertaining to the modeling and design of low-carbon manufacturing operations can be classified into four categories: 1) energy conservation; 2) carbon trade, cap and tax; 3) onsite renewable generation; and 4) renewable power purchase. Research related to each method is reviewed below.

The idea of energy conservation is to increase the machine usage or reduce its idle time so that less electricity is wasted during the production time. Mouzon et al. (2007) propose an 
optimal scheme to shorten the equipment idle time by controlling the on-and-off of underutilized machines, hence minimizing the total energy use. Mashaei and Lennartson (2013) develop a control strategy for a closed-loop flow shop plant based on a pallet system where energy savings are achieved by reducing the machine runtime and the pallet motions. Choi and Xirouchakis (2014) formulate a linear programing model in an aggregate production environment to minimize a weighted objective function that comprises energy, inventory, and backorders. Similarly, Masmoudi et al. (2017) optimize the lot-sizing problem at each production period while minimizing the cost comprised of electrical, inventory, and set-up expense. All these studies revolve around the search for the best production plan or machine schedule to lower the power consumption, hence reducing the carbon emissions.

Emissions cap-and-trade is a market-based mechanism designed to control and curb carbon and pollutant generation, and it has been implemented in many countries. Two prominent examples are the European Union Emissions Trading Scheme and the Sulfur Dioxide Emissions Trading Scheme in the United States. We present hereafter related studies that revolve around the design and operations of production and inventory systems under carbon cap-and-trade scheme. Letmathe and Balakrishnan (2005) develop a mixed integer linear mathematical model to optimize the product mix, operating procedures, and production quantities under environmental regulations and emissions penalties. Their goal is to decide how to sell products and carbon emission allowances such that the total profit is maximized. Hua et al. (2011) and Bouchery et al. (2012) study how firms manage carbon footprints in transportation and warehousing facilities under the cap-and-trade regulation by comparing the optimal cost with that for the classical economic order quantity model. Gong and Zhou (2013) develop a dynamic production model to meet the random market demand by choosing between a costly yet green technology and a cheap but dirty technology. They characterize the optimal emissions trading and production policies to minimize the expected production cost. Hammami et al. (2015) incorporate carbon tax and emission caps in a multi-echelon production-inventory system under lead-time constraints, and show that individual caps can significantly lower the overall emissions, but may paradoxically increase the emissions per unit product. This paper also pursues a low carbon production system, but our approach differs from carbon cap-andtrade in that we directly install and integrate green energy technologies in manufacturing facilities.

In a DG mode, renewable energy units are installed in proximity to the industrial facility for energy supply. Villarreal et al. (2013) design an onsite generation system comprised of WT and PV to power a semiconductor fab. The model is tested in five U.S. fabs under different 
wind and weather conditions, and the optimal capacity mix is determined based on design of experiments and response surface method. Moon el al. (2014) optimize a multi-machine, multiprocess manufacturing scheduling problem by taking into account partial renewable supply from onsite generation and storage system. Li et al. (2017) investigates the technical feasibility of realizing a net-zero carbon manufacturing facility that solely relies on distributed wind and solar power. Pechmann et al. (2016) investigate a virtual power plant consisting of wind, solar, biomass, and storage to satisfy the energy demand of a medium-size manufacturing firm. The results show that adopting a partial self-supply of renewable energy, especially roof-top PV, is lucrative under current renewable incentive scheme in Germany. Similar to these studies, our study also aims to attain low-carbon industrial operations. The main difference is that we synthesize distributed energy with offsite renewable power purchase to achieve zero emissions, while existing onsite generation models usually exclude PPA.

The literature review indicates that there is a lack of quantitative studies in which corporate PPA and onsite DG are integrated to achieve high supply reliability and low energy cost. Motivated by this gap, we formulate a stochastic programming model to minimize the levelized energy cost by optimizing the mix of onsite and offsite renewable power generation. We further derive managerial insights that would be impossible to obtain if PPA and DG are studied separately.

\section{Model Formulation}

\subsection{Integration of Onsite and Offsite Renewables}

We propose a grid-connected DG system to power a manufacturing facility in pursuit of zero-carbon emission target. As shown in Figure 1, the onsite DG system consists of WT, PV, substation, and feed-in tariff (FIT) mechanism, in which onsite WT and PV arrays are owned by the manufacturing firm. FIT is a government policy in which the owner of the DG system can export surplus renewable energy to the main grid and receives monetary compensation as a reward. Since the DG system is connected with the main grid via the substation, the firm can also import offsite renewable energy under PPA. Large wind farms, solar parks and hydropower plants are the main supplier of offsite renewable energy. 


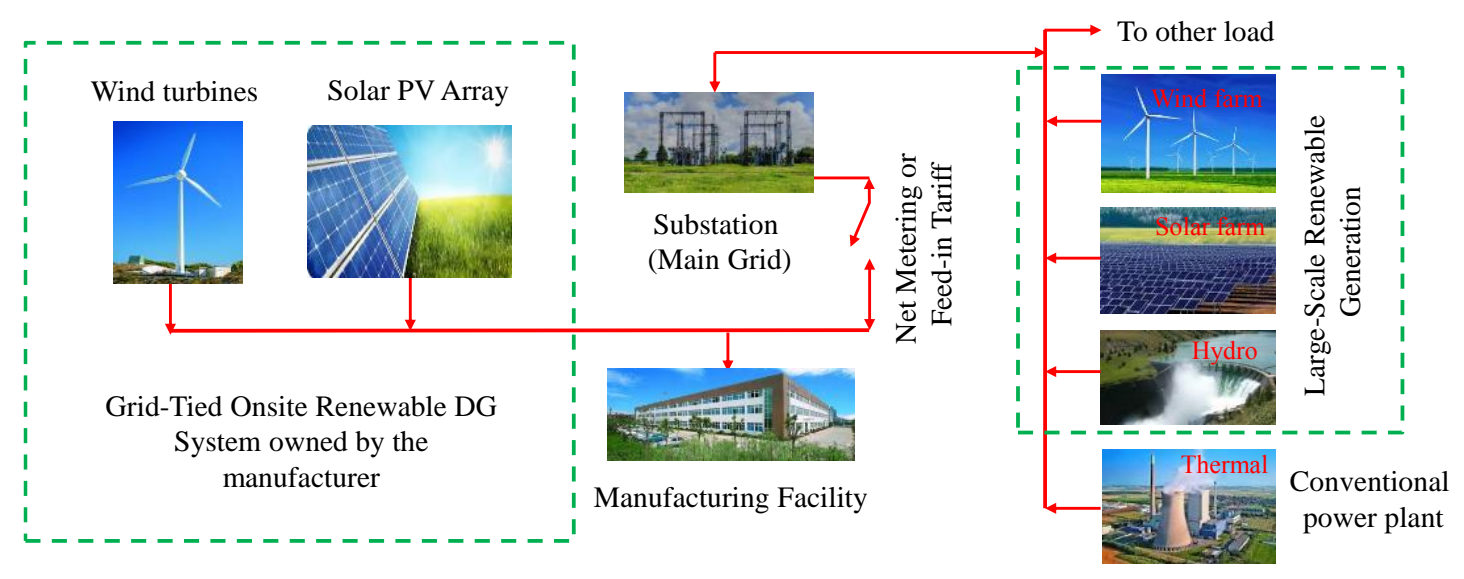

Figure 1: A Hybrid Energy System consisting of DG and PPA Schemes

Three scenarios should be considered in operating a grid-connected DG system. First, if the output power of the DG system is smaller than the demand, the gap can be filled by importing the offsite renewable power through the substation. Second, if the DG output is larger than the demand, the surplus renewable energy can be fed into the main grid via FIT. Third, under PPA, part of or the entire facility's electricity demand can be satisfied by offsite renewable energy suppliers. The facility realizes zero carbon emissions provided that the cumulative electricity use in a year is fully offset by the onsite and/or offsite renewable energy.

Demand response (DR) is a supply-consumption balance scheme in which the electricity consumers change the load profile to better match with the available power. Large industrial firms usually sign a specific DR contract with the utility company, and agreed to curtail the load upon request. In return, the firm participating in DR is able to pay a reduced electricity rate or receive other forms of financial benefits such as a lump-sum payment. The duration of a DR event usually does not exceed eight hours (Baldick et al. 2006). We focus on interruptible/curtailable (I/C) DR contract because it is the most widely used program for large industrial consumers. Let $D_{t}$ be the power demand of the facility at time $t$, and $L_{t}$ be the demand to be curtailed at $t$. The load curtailment of a typical I/C DR event falls in $0<L_{t} \leq 0.2 E\left[D_{t}\right]$.

\subsection{Stochastic Planning Model}

The following notations are used in the zero-carbon facility planning model in this paper. 
Table 1: Notations of DG Planning Model

\begin{tabular}{|c|c|}
\hline Notation & Meaning \\
\hline$\phi$ & capital recovery factor \\
\hline$n$ & number of years to pay off the DG investment cost \\
\hline$r$ & annual interest rate or discount factor \\
\hline$m$ & number of available DER type \\
\hline$a_{i}$ & capacity cost of DER type $i$ (unit: \$/MW) \\
\hline$b_{i}$ & operating and maintenance cost of DER type $i$ (unit: $\$ / \mathrm{MWh}$ ) \\
\hline$c_{i}$ & carbon credits for generating type $i$ (unit: $\$ / \mathrm{MWh}$ ) \\
\hline$h$ & annual operating hours of the facility assuming $24 / 7$ mode \\
\hline$\epsilon$ & production losses in demand response event (unit: $\$ / \mathrm{MWh}$ ) \\
\hline$\rho_{1}$ & price of conventional electricity (unit: $\$ / \mathrm{MWh}$ ) \\
\hline$\rho_{2}$ & price of offsite renewable energy, i.e. the PPA price (unit: $\$ / \mathrm{MWh}$ ) \\
\hline$q$ & feed-in tariff (unit: \$/MWh) \\
\hline$G$ & offsite renewable power purchased (unit: MW) \\
\hline $\mathbf{P}^{c}$ & $\left\{P^{c} 1, P^{c}, \ldots, P_{m}^{c}\right\}$, where $P^{c}$ is the power capacity of DER type $i$ \\
\hline $\mathbf{P}$ & $\left\{P_{1}, P_{2}, \ldots, P_{m}\right\}$, where $P_{i}$ is the random output power of DER type $i$ \\
\hline$D_{t}$ & Electricity demand of the facility at time $t$ (unit: MW) \\
\hline$L_{t}$ & load curtailment level at time $t$ (unit: MW) \\
\hline$Z_{t}$ & Net power of the DG system at time $t$ (unit: MW) \\
\hline
\end{tabular}

The zero-carbon energy generation model is stated as follows: The facility aims to minimize the levelized cost of energy (LCOE) while attaining 100 percent of renewable energy penetration. LCOE is defined as the annualized cost of the energy system divided by the cumulative energy consumed in a year. In power industry, LCOE serves as a basic instrument for both utility companies and energy developers to compare the aggregate costs of capital equipment, operations and maintenance $(\mathrm{O} \& \mathrm{M})$, reliability performance, carbon tax, and government subsidies with different generating technologies and lifetimes (Cory and Schwabe, 2009). Denoted as Model P1, the DG design model is stated as follows.

\section{Model P1:}

Minimize:

$$
\begin{aligned}
f\left(\mathbf{P}^{c}, G\right)= & \frac{1}{\sum_{t=1}^{h}\left(D_{t}-\left\{L_{t}\right\}^{+}\right)}\left\{\phi(n, r) \sum_{i=1}^{m} a_{i} P_{i}^{c}+\sum_{t=1}^{h} \sum_{i=1}^{m}\left(b_{i}-c_{i}\right) P_{i t}+\varepsilon \sum_{t=1}^{h}\left\{L_{t}\right\}^{+}\right. \\
& \left.+h \rho_{2} G+\sum_{t=1}^{h}\left[\left(\rho_{1} I\left(Z_{t}\right)+q I\left(-Z_{t}\right)\right)\left(D_{t}-\sum_{i=1}^{g} P_{i t}-G-\left\{L_{t}\right\}^{+}\right)\right]\right\}
\end{aligned}
$$

Subject to:

$$
Z_{t}=D_{t}-\sum_{i=1}^{g} P_{i t}-\left\{L_{t}\right\}^{+}-G, \text { for } t=1,2, \ldots, h
$$




$$
\begin{aligned}
& \sum_{t=1}^{h}\left(\sum_{i=1}^{g} P_{i t}+\left\{L_{t}\right\}^{+}\right)+h G=\sum_{t=1}^{h} D_{t}, \\
& 0 \leq G \leq E\left[D_{t}\right] \\
& P_{1}{ }^{\mathrm{c}}, P_{2} \mathrm{c}, \ldots, P_{g}^{\mathrm{c}} \geq 0,
\end{aligned}
$$

Note that $\mathbf{P}^{\mathrm{c}}=\left\{P_{1}{ }^{\mathrm{c}}, P_{2} \mathrm{c}, \ldots, P_{g}^{\mathrm{c}}\right\}$ and $G$ are the decision variables. In particular, $\mathbf{P}^{\mathrm{c}}$ represents the power capacity of onsite generation type $i$ for $i=1,2, \ldots, g$, and $G$ is the purchased renewable power. The objective function (1) is formulated to minimize the LCOE in which the numerator is the annualized energy cost and the denominator is the yearly electricity consumption of the facility. The energy cost includes onsite WT and PV installation, O\&M expenses, carbon credits, production loss due to curtailed load, renewable power purchase, utility bills, and feed-in tariff. Note that carbon credits and feed-in-tariff are indeed the incomes of the industrial facility and, therefore, are subtracted from the total cost. The goal is to determine $\mathbf{P}^{c}$ and $G$ such that the LCOE is minimized. $\phi(n, r)=\left[r(1+r)^{n}\right] /\left[(1+r)^{n}-1\right]$ is the capital recovery factor where $r$ is the interest rate, and $n$ is the number of years to pay off the onsite DG equipment cost. Note that $\left\{L_{t}\right\}^{+}=L_{t}$ if $L_{t}>0$, and is 0 if $L_{t} \leq 0$. Also $I\left(Z_{t}\right)$ is the indictor function, and $Z_{t}$ is the net power defined in Equation (2). If $Z_{t}>0$, then $I\left(Z_{t}\right)=1$, or 0 if $Z_{t} \leqslant 0$. If $Z_{t}>0$, it means $D_{t}$ is larger than the sum of the renewable power and the curtailed load, and vice versa. Constraint (3) states that the sum of onsite renewable energy (plus DR curtailment) and the offsite purchased energy in a year equals the total electricity consumption of the facility; hence realizing the zero-carbon emission goal. Constraint (4) defines the cap of PPA which is the mean of the facility load. Constraint (5) states the non-negativity requirements of the decision variables. All other parameters are explained in Table 1.

\subsection{Simulation-Based Optimization Algorithm}

Model P1 is a non-linear, non-smooth stochastic optimization model. Scenario trees and simulation-based optimization algorithm can be used to search for a good solution that is expected be close to the optimal solution. Readers are referred to (Birge and Louveaux 2011, Gosavi 2015) for a complete treatment of global optimization problems using non-traditional computational methods.

This paper adopts the simulation-based optimization to tackle the non-linear programming model in P1. The iterative process to find the optimal $\mathbf{P}$ and $G$ based on simulation-based optimization is described in Figure 2. This simulation algorithm involves three loops 
representing PPA, onsite WT and PV generation. Note that $G^{\max }$ is the upper limit of purchased renewable power, and $P_{i}^{\max }$ is the upper capacity limit of generation type $i$. Both $G^{\max }$ and $P_{i}^{\max }$ can be determined based on the load profile of the facility. Without loss of generality, only loops $i=1$ and 2 are shown in Figure 2. If $m>2$, then there are $m$ loops of incremental operations on $P_{i}=P_{i}+\Delta P_{i}$ for $i=1,2, \ldots, m$. The mathematic models for simulating hourly wind and PV generation are available in (Santana-Viera et al. 2015). For demand responses, we use the same probabilistic model propsoed by $\mathrm{Li}$ et al. (2017) to characterizing the I/C DR contract that involves Poisson calls and uniformly distributed curtailment duration. The optimization algorithm is implemented in MatLab running in Dell PC featuring Intel(R) Core ${ }^{\mathrm{TM}} 2$ Duo CPU @ $2.93 \mathrm{GHz}$ and $8 \mathrm{~GB}$ memory.

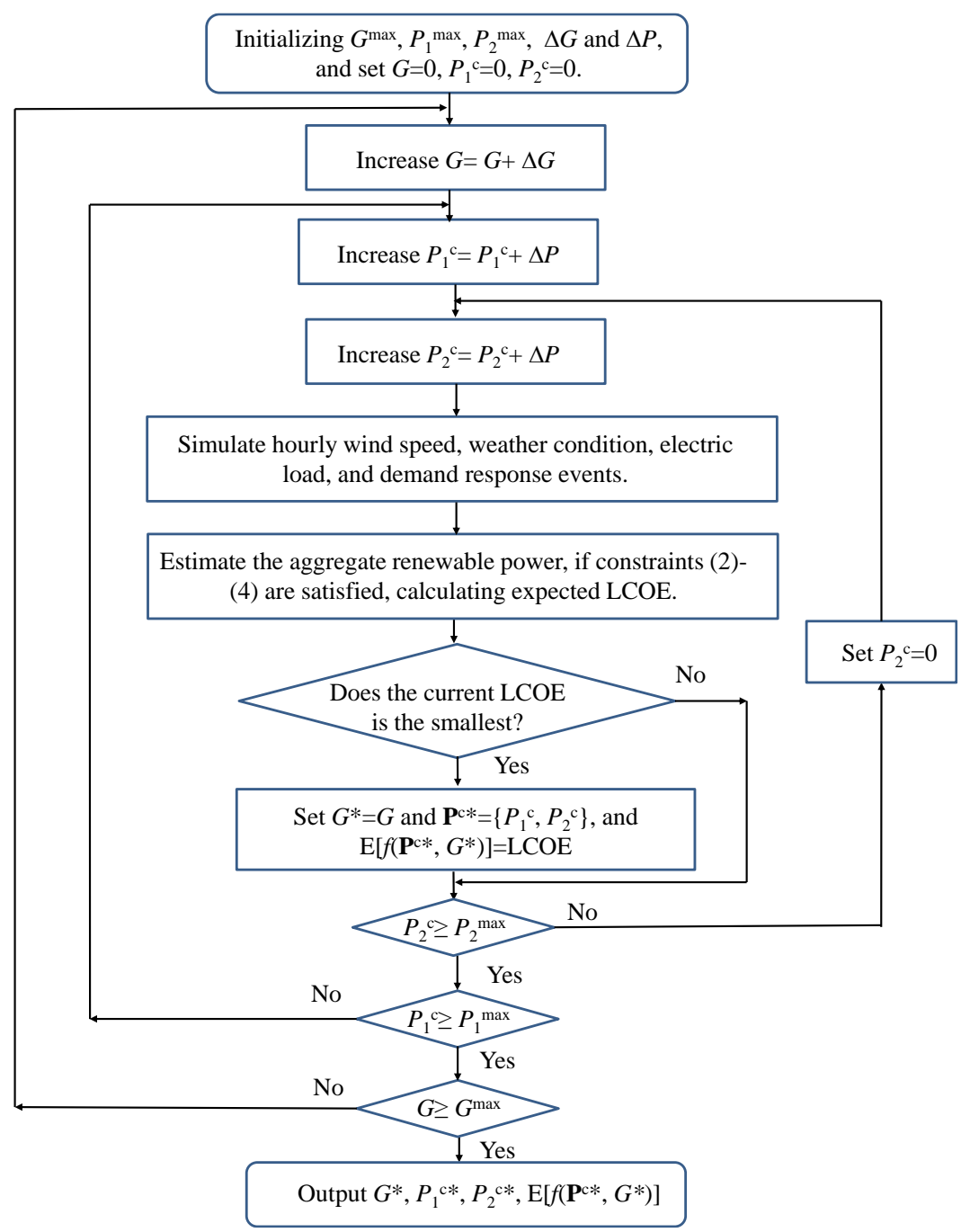

Figure 2: Flow Chart of Optimization Algorithm for PPA, WT and PV

\section{Numerical Study using Design of Experiments (DOE)}

\subsection{Background Information}


The electricity consumption data of a wafer fab in Austin, TX, USA is used to characterize the annual power demand profile. Since the fab facility operates 24 hours a day and 7 days a week, the hourly demand, represented by the mean and standard deviation, is used to capture the fab's electricity consumption profile in each month. As shown in Table 2, the hourly mean demand and its standard deviation capture two piece of information: 1) the daily demand profile by simulating the demand hour-by-hour based on the normal distribution; and 2) the seasonality effect through different mean demand across 12 months. Moreover, according to Table 2, the electric demand between February and March is among the lowest with the average of 8.846 MW and 8.853 MW, respectively. It ramps up from April and reaches the peak at 10.334 MW in September before declining to 9.267 MW in January the next year. Since the facility is physically located in Austin, hot summer weather coupled with market spikes contribute to the variation of electricity demands.

Table 2: Mean and Standard Deviation (Stdev) of Load per Hour (Li et al. 2017)

\begin{tabular}{ccccccc}
\hline Month & January & February & March & April & May & June \\
\hline Mean (MW) & 9.267 & 8.846 & 8.853 & 8.930 & 9.397 & 9.588 \\
Stdev (MW) & 0.232 & 0.221 & 0.221 & 0.223 & 0.235 & 0.240 \\
\hline Month & July & August & September & October & November & December \\
\hline Mean (MW) & 10.068 & 9.983 & 10.334 & 10.237 & 10.093 & 9.448 \\
Stdev (MW) & 0.252 & 0.250 & 0.258 & 0.256 & 0.252 & 0.236 \\
\hline
\end{tabular}

WT and PV are the onsite generating units to be installed near the wafer fab. The cutin, rated and cut-off speeds of WT are $v_{c}=2, v_{r}=10$, and $v_{s}=25 \mathrm{~m} / \mathrm{s}$, respectively. The efficiency of PV panel is $\eta=0.15$, and its operating temperature is assumed be $T_{o}=45^{\circ} \mathrm{C}$. These values, though vary in different location and time, are frequently used in literature as the standards in estimating the wind and solar generation (Freris and Infield, 2008). The lifetimes of WT and PV equipment usually are assumed to be $n=20$ years, and the loan interest rate $r=0.05$. It is common to assume the contingency calls under the I/C DR program follow the Poisson process with $\lambda=5$ calls/year. The maximum curtailment duration is $T_{\max }=8$ hours/event, and the level of each curtailment is $L_{\max }=1.91 \mathrm{MW}$, namely $0.2 E\left[D_{t}\right]$. The actual DR duration and the curtailment level could be smaller than $T_{\max }$ and $L_{\max }$, respectively. We take the extreme values so as to cover the worst DR scenarios in a year. For PPA data, Bolinger et al. (2014) show that the price of renewable power purchase contract continues to decline such that newly contracted 
price can compete with conventional electricity. Hence, we set $\rho_{2}=\$ 70 / \mathrm{MWh}$. Other cost items related to WT and PV are available in Table 3.

Table 3: Cost Parameters of WT and PV Equipment

\begin{tabular}{clccc}
\hline Notation & \multicolumn{1}{c}{ Description } & $\begin{array}{c}\text { DOE } \\
(\text { Section } 4)\end{array}$ & $\begin{array}{c}\text { Testing Cities } \\
(\text { Section } 5)\end{array}$ & Unit \\
\hline$a_{1}$ & Capacity cost of WT & $1.5 \times 10^{6}$ & $1.5 \times 10^{6}$ & $\$ / \mathrm{MW}$ \\
$a_{2}$ & Capacity cost of PV & $4 \times 10^{6}$ & $4 \times 10^{6}$ & $\$ / \mathrm{MW}$ \\
$b_{1}$ & O\&M cost of WT & 14 & 14 & $\$ / \mathrm{MWh}$ \\
$b_{2}$ & O\&M cost of PV & 8 & 8 & $\$ / \mathrm{MWh}$ \\
$\rho_{1}$ & Price of conventional electricity & 70 & 70 or variable & $\$ / \mathrm{MWh}$ \\
$\rho_{2}$ & Price of renewable power in PPA & 70 & 70 or variable & $\$ / \mathrm{MWh}$ \\
$q$ & Feed-in tariff & 70 & 70 & $\$ / \mathrm{MWh}$ \\
$\epsilon$ & Production losses in a DR event & 10,000 & 10,000 & $\$ / \mathrm{MWh}$ \\
$\lambda$ & Demand response call rate & 5 & 5 & Calls/year \\
$T_{\max }$ & Maximum duration of a DR event & 8 & 8 & Hours \\
$L_{\max }$ & Maximum level of curtailed load & 1.91 & 1.91 & MW \\
\hline
\end{tabular}

\subsection{Experimental Setup}

The power output and the energy cost of WT and PV units are determined primarily by three factors: wind speed, weather condition, and site latitude. While WT output is dominated solely by wind speed, the PV output is dependent on the weather condition and the latitude. We apply the design of experiments (DOE) method to investigate how these factors jointly determine the output of the onsite DG system. To that end, a $7 \times 3 \times 2=42$ factorial experiment is performed, corresponding to seven wind speeds, three types of weather condition and two latitudes.

For the wind speed, we increase the mean value from $3 \mathrm{~m} / \mathrm{s}$ to $9 \mathrm{~m} / \mathrm{s}$ with the increment of $1 \mathrm{~m} / \mathrm{s}$. The standard deviation is assumed to be 15 percent of its mean value. We consider three weather conditions: strong sunshine $W_{1}=\{70,20,10\}$, medium sunshine $W_{2}=\{40,30$, $30\}$, and weak sunshine $\mathrm{W}_{3}=\{20,30,50\}$, where the numbers in the bracket represent the percentage of sunny, partially cloudy, and overcasting days across a year, respectively. Given the fact that the majority of the human beings reside between South 45 and North 45 degrees of the Earth, two levels of latitude are considered: 30 and 45 degrees. Due to the symmetry of the Earth, only the latitudes of northern hemisphere are considered. To ease the comparison, 42 designs are classified into 6 cases shown in Table 4. Two additional designs, denoted as 
Cases 7 and 8, are presented to examine whether PV can compete with the wind generation if the equipment cost is reduced to $\$ 1.5 \mathrm{M} / \mathrm{MW}$ and $\$ 1 \mathrm{M} / \mathrm{MW}$, respectively.

Table 4: Levels of Wind Speed, Weather Condition and Latitude

\begin{tabular}{|ccccc|}
\hline Case & Wind Speed & Weather Condition & Latitude & PV (\$M/MW) \\
\hline 1 & $\{3,4,5,6,7,8,9\}$ & $\{70,20,10\}$ & $\{30\}$ & 4 \\
2 & $\{3,4,5,6,7,8,9\}$ & $\{70,20,10\}$ & $\{45\}$ & 4 \\
3 & $\{3,4,5,6,7,8,9\}$ & $\{40,30,30\}$ & $\{30\}$ & 4 \\
4 & $\{3,4,5,6,7,8,9\}$ & $\{40,30,30\}$ & $\{45\}$ & 4 \\
5 & $\{3,4,5,6,7,8,9\}$ & $\{20,30,50\}$ & $\{30\}$ & 4 \\
6 & $\{3,4,5,6,7,8,9\}$ & $\{20,30,50\}$ & $\{45\}$ & 4 \\
\hline 7 & $\{3,4,5,6,7,8,9\}$ & $\{70,20,10\}$ & $\{30\}$ & 1.5 \\
8 & $\{3,4,5,6,7,8,9\}$ & $\{70,20,10\}$ & $\{30\}$ & 1.0 \\
\hline
\end{tabular}

\subsection{Results Analysis and Discussion}

For each design in Table 4, Model P1 is solved to minimize the LCOE by finding the optimal generation mix of purchased power $G$, WT capacity $P_{1}{ }^{\mathrm{c}}$, and PV capacity $P_{2}{ }^{\mathrm{c}}$. Since $E\left[D_{t}\right]=9.587 \mathrm{MW}$, the capacity of $G$ is assumed to be an integer taking a value from $\{0,1, \ldots$, 9 \}. Note that $G=10 \mathrm{MW}$ is not considered because it exceeds $E\left[D_{t}\right]$. A total of 42 instances are optimized and the results of each instance are summarized in Table 5. The following observations are made from Cases 1 to 6.

- As anticipated, the LCOE decreases with the wind speed regardless of the weather condition and the latitude. If wind speed is $6 \mathrm{~m} / \mathrm{s}$ or lower, then LCOE falls in a range between $\$ 76 / \mathrm{MWh}$ and $\$ 97 / \mathrm{MWh}$. If wind speed reaches $9 \mathrm{~m} / \mathrm{s}$, then LCOE drops to a lower range between $\$ 40 / \mathrm{MWh}$ and $\$ 48 / \mathrm{MWh}$.

- Regardless of the weather condition and the latitude, with $\rho_{2}=\$ 70 / \mathrm{MWh}, \mathrm{PPA}$ is preferred if the local wind speed is less than $6 \mathrm{~m} / \mathrm{s}$. The optimal offsite power is 8-9 MW, covering the majority of the facility's demand. Onsite wind generation starts to displace PPA if the wind speed reaches or exceeds $7 \mathrm{~m} / \mathrm{s}$.

- Given that the installation cost of PV is \$4M/MW (i.e., 1.67 times higher than WT), there is no cost advantage to use PV even under the strong sunny weather $\mathrm{W}_{1}$. In Cases 1 and 2 where the overcast days are only $10 \%$ in a year, PPA is still preferred over onsite PV as long as the local wind speed is $6 \mathrm{~m} / \mathrm{s}$ or less. Obviously, the small amount of PV installation in Cases 1 and 2 simply offset the demand spike of the industrial facility. 
Table 5 Optimal Generation Mix for Cases 1 to 8

\begin{tabular}{|c|c|c|c|c|c|c|c|c|c|}
\hline Wind & Case & 1 & 2 & 3 & 4 & 5 & 6 & 7 & 8 \\
\hline \multirow{4}{*}{$3(\mathrm{~m} / \mathrm{s})$} & PPA (MW) & 9.0 & 9.0 & 9.0 & 9.0 & 9.0 & 9.0 & 9.0 & 0.0 \\
\hline & WT (MW) & 0.0 & 0.2 & 0.0 & 0.8 & 0.5 & 0.8 & 0.0 & 0.2 \\
\hline & PV (MW) & 3.0 & 3.2 & 3.5 & 3.5 & 4.2 & 4.5 & 3.0 & 43.8 \\
\hline & LCOE (\$/MWh) & 88.3 & 87.3 & 89.8 & 93.5 & 97.2 & 95.5 & 84.6 & 63.4 \\
\hline \multirow{4}{*}{$4(\mathrm{~m} / \mathrm{s})$} & PPA (MW) & 9.0 & 9.0 & 9.0 & 9.0 & 9.0 & 9.0 & 9.0 & 0.0 \\
\hline & WT (MW) & 0.5 & 0.5 & 3.0 & 3.7 & 3.8 & 4.0 & 0.0 & 0.3 \\
\hline & PV (MW) & 2.5 & 2.8 & 2.2 & 2.2 & 2.3 & 2.5 & 3.0 & 43.5 \\
\hline & LCOE (\$/MWh) & 87.4 & 86.8 & 87.8 & 87.1 & 89.8 & 90.7 & 83.5 & 56.5 \\
\hline \multirow{4}{*}{$5(\mathrm{~m} / \mathrm{s})$} & PPA (MW) & 9.0 & 9.0 & 9.0 & 9.0 & 9.0 & 9.0 & 9.0 & 0.0 \\
\hline & WT (MW) & 4.5 & 4.0 & 4.0 & 4.0 & 4.0 & 4.0 & 0.0 & 0.0 \\
\hline & PV (MW) & 0.0 & 0.5 & 0.5 & 0.5 & 0.5 & 0.5 & 3.0 & 44.0 \\
\hline & LCOE (\$/MWh) & 83.9 & 83.3 & 82.4 & 81.3 & 79.5 & 86.8 & 84.5 & 52.0 \\
\hline \multirow{4}{*}{$6(\mathrm{~m} / \mathrm{s})$} & PPA (MW) & 8.5 & 9.0 & 9.0 & 8.0 & 8.0 & 8.0 & 9.0 & 0.0 \\
\hline & WT (MW) & 5.0 & 2.5 & 2.5 & 7.0 & 7.0 & 7.0 & 0.7 & 0.3 \\
\hline & PV (MW) & 0.0 & 0.2 & 0.5 & 0.0 & 0.0 & 0.0 & 2.3 & 43.2 \\
\hline & LCOE (\$/MWh) & 79.5 & 77.6 & 80.4 & 76.1 & 79.7 & 83.3 & 88.2 & 58.2 \\
\hline \multirow{4}{*}{$7(\mathrm{~m} / \mathrm{s})$} & PPA (MW) & 0.0 & 0.0 & 0.3 & 0.0 & 0.0 & 0.0 & 0.0 & 0.0 \\
\hline & WT (MW) & 26.0 & 26.2 & 25.2 & 26.2 & 26.2 & 26.3 & 25.8 & 1.3 \\
\hline & PV (MW) & 0.0 & 0.3 & 0.5 & 0.2 & 0.3 & 0.2 & 0.8 & 41.8 \\
\hline & LCOE (\$/MWh) & 67.4 & 63.4 & 73.4 & 57.1 & 68.8 & 62.8 & 66.3 & 57.7 \\
\hline \multirow{4}{*}{$8(\mathrm{~m} / \mathrm{s})$} & PPA (MW) & 0.0 & 0.0 & 0.0 & 0.0 & 0.0 & 0.0 & 0.0 & 0.0 \\
\hline & WT (MW) & 17.5 & 17.5 & 17.5 & 17.8 & 17.8 & 17.7 & 17.5 & 17.3 \\
\hline & PV (MW) & 1.0 & 0.7 & 0.8 & 0.2 & 0.2 & 0.3 & 0.3 & 1.2 \\
\hline & LCOE (\$/MWh) & 51.2 & 50.2 & 52.5 & 48.6 & 49.9 & 49.1 & 48.4 & 55.5 \\
\hline \multirow{4}{*}{$9(\mathrm{~m} / \mathrm{s})$} & PPA (MW) & 0.0 & 0.0 & 0.0 & 0.0 & 0.0 & 0.0 & 0.0 & 0.0 \\
\hline & WT (MW) & 13.0 & 13.0 & 13.0 & 13.5 & 13.5 & 13.5 & 13.0 & 17.5 \\
\hline & PV (MW) & 0.5 & 1.0 & 1.0 & 0.0 & 0.0 & 0.0 & 0.7 & 0.5 \\
\hline & LCOE (\$/MWh) & 46.6 & 39.5 & 48.7 & 42.7 & 39.0 & 42.9 & 47.9 & 52.0 \\
\hline
\end{tabular}

Cases 7 and 8 aim to analyze how the PV installation cost influences its penetration rate in a hybrid energy portfolio comprised of PPA and WT. With the advancement of design and manufacturing technologies, it is foreseeable that the PV cost will continue to decline in the next 10-20 years. We solve Model P1 by lowering the PV cost from $\$ 4 \mathrm{M} / \mathrm{MW}$ to $\$ 1.5 \mathrm{M} / \mathrm{MW}$ and $\$ 1 \mathrm{M} / \mathrm{MW}$ so that the costs of PV and WT are comparable. Under the strong sunny weather $\mathrm{W}_{1}$ with latitude $30^{\circ}$, we search for the optimal generation mix and the results are shown in the two rightmost columns of Table 5. Two observations can be made by comparing Case 7 with Case 1. First, Case 7 shows that at $\$ 1.5 \mathrm{M} / \mathrm{MW}$, PV can compete with wind generation if the local wind speed is less than $6 \mathrm{~m} / \mathrm{s}$; however, PPA is still preferred over PV because of low 
cost. Second, Case 8 shows that if the PV cost drops to \$1M/MW, PV can displace PPA and WT in areas where the wind speed is $7 \mathrm{~m} / \mathrm{s}$ or less. Above that speed, WT takes over PV and PPA.

\subsection{Discussion of DG Stability}

In a conventional power grid, electric energy can only flow from central power plants to end consumers through transmission and distribution lines. With the advent of onsite DG systems, bi-directional power flow becomes possible and necessary. Since utility-scale storage systems are still costly to implement, surplus power from local DG system has to be fed into the main grid under FIT scheme. However, reverse current may cause voltage stability issue, and also create dispatch challenges due to the intermittency of renewable generation. To maintain the grid stability, a common practice is that surplus power exported to the grid is consumed locally. This design criterion is reflected in Constraint (3) where the annual demand is exactly offset by the onsite and offsite renewable generation. Hence, it reduces the amount of surplus power exported to the main grid, and maintains the voltage at a stable level.

\section{Application in Real-Word Environment}

\subsection{Background Introduction}

The cities from Li et al. (2017) are used to test the proposed DG and PPA model, and the information about latitude, wind speed and weather condition are duplicated in Table 6. The climatic data of each city are retrieved from the National Climate Date Center (NCDC 2014) and Weather Underground (WU 2014). The daily wind speed data are recorded by the Automated Surface Observing Systems (ASOS) that are typically situated in the local airport, and the ASOS wind sensors are placed 8-10 meters above the ground. Note that Rio Gallegos and Wellington are located in the southern hemisphere. The rest of the cities are in the northern hemisphere. In particular, Shanghai, Sanya and Tokyo are in Asia. Munich is in Europe. Boston, New York and Phoenix are in North America, and Honolulu is on the Pacific island. Since the latitude of these cities varies between 18.25 and 51.63 degrees in both northern and southern hemispheres, these sites cover the majority of the regions where the people live. 
Table 6: Wind Speed and Weather Condition of Ten Cities (Li et al. 2017)

\begin{tabular}{ccccccccc}
\hline No. & City & Country & $\begin{array}{c}\text { Latitude } \\
(\text { degree })\end{array}$ & $\begin{array}{c}\text { AWS } \\
(\mathrm{m} / \mathrm{s})\end{array}$ & $\begin{array}{c}\text { SWS } \\
(\mathrm{m} / \mathrm{s})\end{array}$ & $\begin{array}{c}\text { Sunny } \\
(\text { days })\end{array}$ & $\begin{array}{c}\text { PC } \\
(\text { days })\end{array}$ & $\begin{array}{c}\text { Overcasti } \\
\text { ng (days) }\end{array}$ \\
\hline 1 & Rio Gallegos & Argentina & 51.63 & 7.16 & 1.07 & 144 & 84 & 137 \\
2 & Shanghai & China & 31.20 & 5.02 & 2.15 & 181 & 41 & 140 \\
3 & Sanya & China & 18.25 & 6.51 & 3.11 & 235 & 42 & 88 \\
4 & Munich & Germany & 48.13 & 5.14 & 1.04 & 65 & 110 & 190 \\
5 & Tokyo & Japan & 35.68 & 5.22 & 0.40 & 179 & 22 & 164 \\
6 & Wellington & New Zealand & 41.29 & 8.05 & 1.21 & 79 & 100 & 186 \\
7 & Phoenix & USA & 33.30 & 2.78 & 0.32 & 211 & 85 & 70 \\
8 & Boston & USA & 42.36 & 5.68 & 0.56 & 168 & 64 & 133 \\
9 & Honolulu & USA & 21.30 & 5.09 & 0.50 & 169 & 39 & 157 \\
10 & New York & USA & 40.71 & 5.30 & 0.60 & 107 & 102 & 156 \\
\hline
\end{tabular}

Note: $\mathrm{AWS}=$ average wind speed, $\mathrm{SWS}=$ standard deviation of wind speed, $\mathrm{PC}=$ partially cloudy

Table 7: Carbon Credits and Utility Price (utility means conventional electricity)

\begin{tabular}{ccccccc}
\hline Case & $\begin{array}{c}c_{1} \\
(\$ / \mathrm{MWh})\end{array}$ & $\begin{array}{c}c_{2} \\
(\$ / \mathrm{MWh})\end{array}$ & $\begin{array}{c}\rho_{1} \\
(\$ / \mathrm{MWh})\end{array}$ & $\begin{array}{c}\rho_{2} \\
(\$ / \mathrm{MWh})\end{array}$ & $\begin{array}{c}\text { Utility } \\
\text { Pricing }\end{array}$ & $\begin{array}{c}\text { PV Cost } \\
(\$ \mathrm{M} / \mathrm{MW})\end{array}$ \\
\hline $\mathrm{A}$ & 0 & 0 & 70 & 70 & Flat & 4.0 \\
$\mathrm{~B}$ & 0 & 0 & 70 & 50 & Flat & 4.0 \\
$\mathrm{C}$ & 0 & 35 & 70 & 70 & Flat & 4.0 \\
$\mathrm{D}$ & 0 & 0 & 70 & 70 & $3 \%$ up & 4.0 \\
\hline
\end{tabular}

To cover a variety of generation scenarios, we investigate five cases subject to different carbon credit, feed-in tariff, utility price and PV installation cost. The data are obtained from the literature and government reports with the best effort to reflect the reality (Freris and Infield 2008, NREL 2013). The U.S. government uses $\$ 37 /$ ton as the "social cost" of carbon to guide current energy regulation policies (Moore and Diaz, 2015). Here the carbon credit of \$35/MWh is used because to generate $1 \mathrm{MWh}$, the carbon emission is close to one ton using coal. As shown in Table 7, Case A serves as the benchmark with a flat rate of $\$ 70 / \mathrm{MWh}$ for conventional electricity and no carbon credits to onsite wind and solar generation. Cases B is designed to estimate the LCOE assuming the PPA price is reduced from \$70/MWh to \$50/MWh. In Case $\mathrm{C}$, we estimate the LCOE when $\$ 35 / \mathrm{MWh}$ carbon credit is granted to onsite PV. Carbon credit to WT is not considered as wind generation has been cost-effective. Case D aims to analyze whether LCOE will change significantly if the conventional utility price increases $3 \%$ annually. 
Finally, in Case E, we reduce the PV cost from $\$ 4 \mathrm{M} / \mathrm{MW}$ to $\$ 1.5 \mathrm{M} / \mathrm{MW}$, and compare its competitiveness with PPA and WT. Other parameters related to Model P1 are referred to Tables 2 and 3 .

\subsection{Result Discussions and Future Studies}

For each city, we solve Model P1 and determine the optimal generation mix of PPA, WT and PV for the given parameters. As shown in Figure 3(a), in the benchmark of Case A, PPA is preferred over onsite wind and solar generation in locations where the average wind speed is less than $6.5 \mathrm{~m} / \mathrm{s}$. However, in Rio Gallegos, Sanya and Wellington, onsite WT is more economical than PPA and PV. Though Phoenix possesses the strongest sunshine, PPA turns out of be more cost-effective than onsite PV as the latter involves high installation cost.

In Case B, we reduce the PPA price from $\$ 70 / \mathrm{MWh}$ to $\$ 50 / \mathrm{MWh}$. From Figure 3(b) it is interesting to see that onsite wind generation remains competitive in Rio Gallegos and Wellington, but Sanya now has a mixed capacity of 7MW PPA and 8 MW WT. This example shows that onsite wind generation still can compete with PPA at a rate of $\$ 50 / \mathrm{MWh}$, provided that the local average wind speed is above $7 \mathrm{~m} / \mathrm{s}$.

In Case C, Model P1 is solved for the optimal generation mix assuming that onsite PV receives $\$ 35 / \mathrm{MWh}$ carbon credit. By comparing to Case A, the results in Figure 3(c) show that carbon credit has limited effect to incentivize the adoption of onsite PV because the current energy cost of PPA and WT are far below the LCOE of PV.

In Case D, we assume that the conventional electricity price increases three percent annually. This means $\rho_{1}=\$ 70 / \mathrm{MWh}$ in year 1 , and it goes up to $\$ 122.7 / \mathrm{MWh}$ in year 20. Since PPA is typically a long term contract with larger renewable energy developers, it is reasonable to assume that the price of PPA remains at $\rho_{1}=\$ 70 / \mathrm{MWh}$ over a 20 -year horizon (Baker and McKenzie 2015, Bolinger et al. 2015). We expect that LCOE may increase as a result of the increased rate of conventional electricity. By comparing the corresponding cities between Figures 3(a) and 3(d), there is no obvious change in both capacity mix and LCOE. This observation indicates that manufacturing companies who participate in PPA or adopt onsite renewable generation can avoid the price volatility in the spot or wholesale electricity market. 

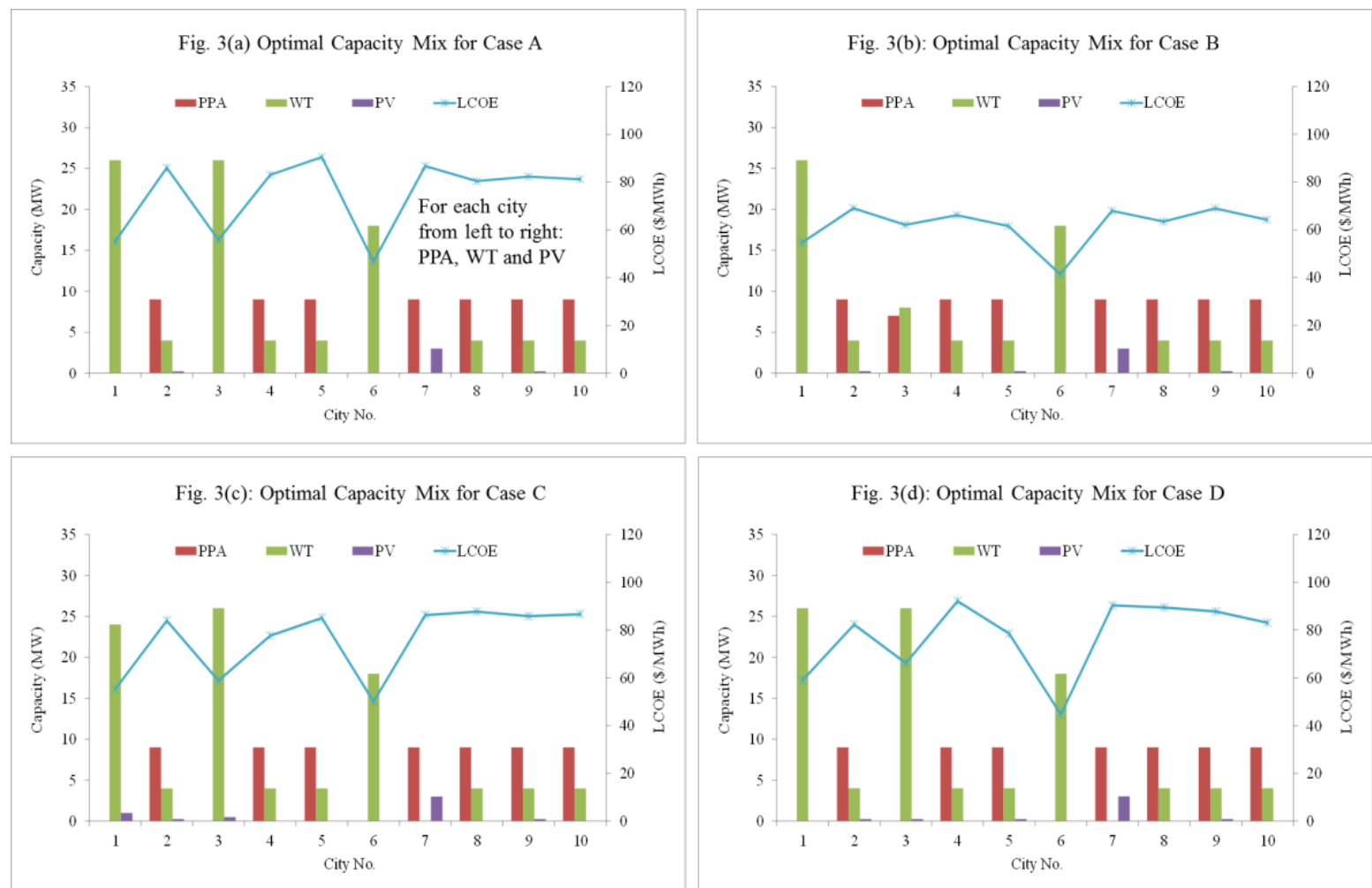

Figure 3: Optimal Capacity Mix and LCOE for Cases A to D

Seasonality is a common phenomenon often observed in wind and solar generation. For instance, the wind profile in winter or spring of a particular site could be stronger than in summer or fall, or vice versa. In this paper, since the LCOE is defined as the annualized system cost divided by the total renewable energy output over a year (see Objective function (1) and Constraint (3)), seasonality has limited effects on the annual renewable generation as we consider the aggregate power across the year. In addition, the DG system in this paper is connected with the main grid under feed-in tariff scheme (FIT). Such grid-tied configuration streamlines or mitigates the seasonality effort because of the power exchange between the DG and the main grid. However, incorporating the seasonality effect becomes necessary if the DG system operates in islanded mode (i.e., disconnected from the main grid). We agree that this topic deserves further investigations in future studies.

\section{Conclusion}

This paper proposes a hybrid energy supply model to achieve carbon-neutral industrial operations through the integration of onsite renewable generation and power purchase agreement. To minimize the levelized cost of energy, simulation-based optimization is used to search for the optimal capacity mix of offsite and onsite wind and solar power. The hybrid 
energy solution is tested under a three-factorial design that includes nine levels of wind speed, three types of weather conditions and two site latitudes. The results show that WT is preferred over PPA if the average wind speed is above $7 \mathrm{~m} / \mathrm{s}$. PPA is more cost-effective than onsite WT if the local wind speed is below $6 \mathrm{~m} / \mathrm{s}$. Onsite PV becomes competitive only if the installation cost drops to $\$ 1.5 \mathrm{M} / \mathrm{MW}$. The model is further tested in ten cities of the world, and the results are consistent with the findings from the factorial design of experiments. First, PPA is a costeffective approach to achieving zero-carbon industrial operations offered at $\$ 70 / \mathrm{MWh}$. However, onsite wind generation shows a better economic performance if the local wind speed is above $6.5 \mathrm{~m} / \mathrm{s}$. Second, PPA and onsite generation can avoid or mitigate the variation and increase of utility price in the long run.

For future studies, the proposed zero-carbon manufacturing model can be extended to supply chain systems that involve production, transportation, warehousing and retail facilities. One can also relax the net-zero emission constraint by incorporating emerging technologies, such as virtual power plants, vehicle-to-grid operations, and transactive energy systems.

\section{References}

Aalami, H. A., Moghaddam, M.P., Yousefi, G. R., 2010. Demand response modeling considering interruptible/curtailable loads and capacity market programs. Applied Energy, 87(1), 243-250.

Baker \& McKenzie, 2015. The rise of corporate PPAs: A new driver for renewables. Available at http://www.bakermckenzie.com/-/media/files/insight/publications/2015/12/the-rise-ofcorporate-ppas/report_re_corporateppas_20151202.pdf?la=en, page 4, (on August 26, 2017).

Baldick, R., Kolos, S., Tompaidis, S., 2006. Interruptible electricity contracts from an electricity retailer's point of view: valuation and optimal interruption. Operations Research, 54(4), 627-642.

Birge, J. R., Louveaux, F., 2011. Introduction to stochastic programming (2nd ed). New York, USA: Springer Science \& Business Media. 
Bolinger, M., Weaver, S., Zuboy, J., 2015. Is \$50/MWh solar for real? Falling project prices and rising capacity factors drive utility-scale PV toward economic competitiveness. Progress in Photovoltaics: Research and Applications, 23(12), 1847-1856.

Bouchery, Y., Ghaffari, A., Jemai, Z., Dallery, Y., 2012. Including sustainability criteria into inventory models. European Journal of Operational Research, 222(2), 229-240.

Choi, Y. C., Xirouchakis, P., 2014. A production planning in highly automated manufacturing system considering multiple process plans with different energy requirements. The International Journal of Advanced Manufacturing Technology, 70(5-8), 853-867.

Cory, K., Schwabe, P., 2009. Wind levelized cost of energy: A comparison of technical and financing input variables. Technical Report NREL/TP-6A2-46671. Available at http://www.nrel.gov/docs/fy10osti/46671.pdf, (accessed on August 26, 2017).

EIA (The U.S. Energy Information Administration), 2016. Greenhouse gases equivalencies calculator —calculations and references. Chapter 16, https://www.epa.gov/energy/greenhousegases-equivalencies-calculator-calculations-and-references, (accessed on August 26, 2017).

Freris, L., Infield, D., 2008. Renewable Energy in Power Systems, Chapter 7, West Sussex, UK: John Wiley \& Sons.

Gong, X., Zhou, S. X., 2013. Optimal production planning with emissions trading. Operations Research, 61(4), 908-924.

Gosavi, A., 2015. Simulation-Based Optimization: Parametric Optimization Techniques and Reinforcement Learning ( $2^{\text {nd }}$ ed). New York, USA: Spinger Publisher.

Hammami, R., Nouira, I., Frein, Y., 2015. Carbon emissions in a multi-echelon productioninventory model with lead time constraints. International Journal of Production Economics, 164, 292-307. 
Hickey, B., 2014, Anheuser-Busch brewing up some wind, solar power, KCRA News Archive, August 14, 2014, available at http://www.kcra.com/article/anheuser-busch-brewing-up-somewind-solar-power/6416039, (accessed on August 26, 2017).

Hu, S. C., Chuah, Y. K., 2003. Power consumption of semiconductor fabs in Taiwan. Energy, 28(8), 895-907.

Hua, G., Cheng, T. C. E., Wang, S., 2011. Managing carbon footprints in inventory management. International Journal of Production Economics,132(2), 178-185.

Huddleston, T. Jr., 2015. Google's latest renewable energy investment is its biggest ever. Fortune, December 3, 2015. Available at http://fortune.com/2015/12/03/google-renewableenergy/, (accessed on August 26, 2017).

International Energy Agency (IEA), 2008. Energy technology perspectives 2016: Scenarios and strategies to 2050. Available at http://www.iea.org/media/etp/etp2008.pdf, (accessed on July 17, 2017).

Letmathe, P., Balakrishnan, N., 2005. Environmental considerations on the optimal product mix. European Journal of Operational Research, 167(2), 398-412.

Li, B., Tian, Y., Chen, F., Jin, T., 2017. Toward net-zero carbon manufacturing operations: An onsite renewables solution. Journal of the Operational Research Society, 68(3), 308-321.

Masmoudi, O., Yalaoui, A., Ouazene, Y., Chehade, H., 2017, Lot-sizing in a multi-stage flow line production system with energy consideration. International Journal of Production Research, 55(6), 1640-1663.

Mashaei, M., Lennartson, B., 2013, Energy reduction in a pallet-constrained flow shop through on-off control of idle machines. IEEE Transactions on Automation Science and Engineering, 10(1), 45-56. 
Moon, J. Y., Park, J., 2014. Smart production scheduling with time-dependent and machinedependent electricity cost by considering distributed energy resources and energy storage. International Journal of Production Research, 52(13), 3922-3939.

Moore, F. C., Diaz, D. B., 2015. Temperature impacts on economic growth warrant stringent mitigation policy. Nature Climate Change, 5(2), 127-131.

Mouzon, G., Yildirim, M. B., Twomey, J., 2007. Operational methods for minimization of energy consumption of manufacturing equipment. International Journal of Production Research, 45(18-19), 4247-4271.

NCDC (National Climate Data Center), 2014. Available at http://www.ncdc.noaa.gov/, (accessed December 10, 2015).

NREL (National Renewable Energy Laboratory), 2013. Distributed generation renewable energy estimate of costs. Available at http://www.nrel.gov/analysis/tech_lcoe_re_cost_est.html, (accessed May 7, 2015).

Oven, B., 2014. The Rise of Distributed Power. Available at https://www.ge.com/sites/default/files/2014\%2002\%20Rise\%20of\%20Distributed\%20Power. pdf, (accessed on August 26, 2017).

Pechmann, A., Schöler, I., Ernst, S., 2016. Possibilities for CO 2-neutral manufacturing with attractive energy costs. Journal of Cleaner Production, 138, 287-297.

Staple G. C., Bromaghim, G., 2015. Google is just a small slice in the new corporate PPA boom. Available at https://www.greenbiz.com/article/google-just-small-slice-new-corporateppa-boom, (accessed on August 26, 2017).

Stinpetru, L., 2014. Honda installs wind turbines at manufacturing plant in Ohio, US, January 23, 2014. Available at http://news.softpedia.com/news/Honda-Installs-Wind-Turbines-atManufacturing-Plant-in-Ohio-US-419798.shtml, (accessed on August 26, 2017). 
Tang, L., Meng, Y., Wang, G., Chen, Z. L., Liu, J., Hu, G., Chen, L., Zhang, B., 2014. Operations Research transforms Baosteel's operations. Interfaces, 44(1), 22-38.

Villarreal, S., Jimenez, J. A., Jin, T., Cabrera-Rios, M., 2013. Designing a sustainable and distributed generation system for semiconductor wafer fabs. IEEE Transactions on Automation Science and Engineering, 10(1), 16-26.

Santana-Viera, V., Jimenez, J., Jin, T., Espiritu, J., (2015), Implementing factory demand response via onsite renewable energy: a design-of-experiment approach, International Journal of Production Research, 53(23), 7034-7048.

WU (Weather Underground), 2014. Available at http://www.wunderground.com/, (accessed on November 10, 2015). 